\title{
Effectiveness of Motion Infographic Media on the Improvement of Knowledge and Medical Adherence in Human Immunodeficiency Virus Patients
}

\author{
JONGKONNEE CHONGPORNCHAI, N. PHORNPRAPA AND L. SRATTHAPHUT2* \\ Pharmacy Department, Saraburi Hospital, Saraburi, 18000, ${ }^{1}$ Department of Pharmacy, Faculty of Pharmacy, ${ }^{2}$ Department of \\ Health-Related Informatics, Faculty of Pharmacy, Silpakorn University, Nakhon Pathom 73000, Thailand
}

Chongpornchai et al.: Infographic Effect on Human Immunodeficiency Virus Knowledge and Medical Adherence

\begin{abstract}
The study aimed to examine the effectiveness of motion infographic media on improving patient's knowledge and medical adherence during counseling. Eighty eight human immunodeficiency virus infected patients from outpatient department, human immunodeficiency virus clinic, Saraburi hospital participated in the study. Subjects were randomized into control and study groups (44 of each). Subjects in the study group received motion infographic media, while those in the control group did not receive motion infographic media. The results showed that subjects in the study group had higher knowledge scores and higher percentage of medical adherence than those in the control group in all tests. In addition, knowledge and medical adherence after receiving motion infographic media in the study group were even greater as indicated by higher knowledge test scores and higher percentage of medical adherence, as compared to before receiving the motion infographic media. It can be concluded that motion infographic media is beneficial and can be used as a tool for improving patient's knowledge and medical adherence during counseling.
\end{abstract}

Key words: Antiretroviral drugs, human immunodeficiency virus, infographics, medical adherence, pharmacist, counseling

Medical adherence is one of the important factors influencing treatment effectiveness in human immunodeficiency virus (HIV) infected patients receiving antiretroviral drugs ${ }^{[1-3]}$. Strict medical adherence leads to a better immune function, a lower chance of viral resistance and a reduced viral load. Generally, antiretroviral regimens can cause the inconsistency of medical adherence due to a number of pills to be taken, a high frequency of medication intake, the difficulties in keeping the medicine and the medication side effects. Even though there have been attempts to improve medical adherence, for instance, prescribing fixed drug combination, taking multiple medications for different times at once and developing of new regimen to reduce side effects, inconsistent medication behaviors still occur and might lead to unsuccessful treatment ${ }^{[4,5]}$.

Several factors have been found influencing medical adherence. Knowledge regarding HIV infection and antiretroviral drugs is one of those factors. Pharmacist as a healthcare provider can play a significant role

*Address for correspondence

E-mail: sratthaphut_L@su.ac.th

May-June 2021 in improving medical adherence through patient counseling and education ${ }^{[6-8]}$. However, inadequacy of pharmacists as well as miscommunication between pharmacists and patients makes the counseling difficult. Integration of technology into the process of counseling may provide more effective outcome.

Infographic media is one of the most recent and effective communication technologies that can be used in the field. It applies images to convey the information or knowledge, which can stimulate the interest of patients, reduce the time used in deducing the intended information, provide a positive impact on the long-term data memorization and influence the behavioral changes of patients ${ }^{[9-13]}$. The objective This is an open access article distributed under the terms of the Creative
Commons Attribution-NonCommercial-ShareAlike 3.0 License, which
allows others to remix, tweak, and build upon the work non-commercially,
as long as the author is credited and the new creations are licensed under
the identical terms

Accepted 04 June 2021

Revised 05 February 2021

Received 01 November 2019 Indian J Pharm Sci 2021;83(3):562-568 
of this study is to integrate motion infographic media (MIM) into counseling process and further examine its effectiveness on improving knowledge and medical adherence of patients who receive antiretroviral drugs.

\section{MATERIALS AND METHODS}

\section{Conceptual framework of infographic media:}

MIM was adapted from the previous work of Chongpornchai, et al. ${ }^{[14]}$. Conceptual framework of the media was obtained from academic documents and operation manuals ${ }^{[4,5,15]}$, along with the survey and inspection from clinical pharmacist at a HIV clinic. Knowledge content was divided into two parts: HIV infection and antiretroviral drugs. The screenshot in fig. 1 displayed MIM examples, which explained information related to HIV infection and antiretroviral drugs in Thai language.

\section{Study site and subjects:}

The study was conducted at Outpatient department, HIV clinic, Saraburi hospital from September 2018 to November 2018. Subject inclusion criteria were as follows: participant was a HIV-infected patient, had age older than $18 \mathrm{y}$, received antiretroviral drugs for more than $1 \mathrm{mo}$, had signed an informed consent form, resided in Saraburi province until completion of the study and did not have difficulties in listening, speaking, reading and writing Thai language and did not have memory disorders.

\section{Ethical considerations:}

The study has been approved by the Human Research Ethics Committee of Faculty of Pharmacy, Silpakorn University (COA no.7/2018). Each participant gave a written informed consent before enrolment. The trial was registered on the Thai Clinical Trials Registry, number TCTR20180725003.

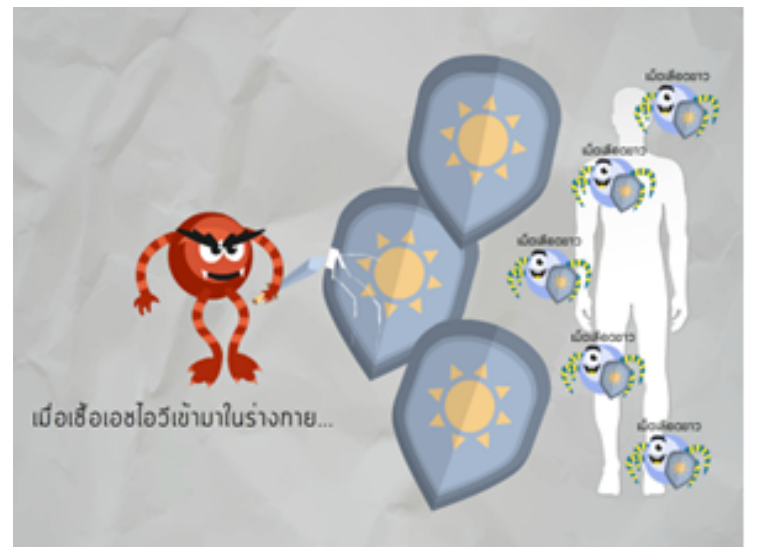

Fig. 1: Screenshot of MIM examples related to HIV infection and antiretroviral drugs
It was a randomized experimental study. Sample size calculation was based on the result from Robbins $\mathrm{RN}$, et al. ${ }^{[16]}$ as medical adherence was assessed using pill count method. Eighty eight subjects were randomized into control and study groups using a random number table that resulted in equal sample sizes $(\mathrm{N}$ of each $=44)$. Subjects on both groups received counseling on HIV infection and antiretroviral drugs. However, MIM was exclusively provided to those in the study group. Fig. 2 displayed the room used for providing MIM to subjects in the study group. After completion of the study, only 34 subjects in the study group and 35 subjects in the control group remained for data analysis as some subjects were lost for follow-up on the second visit.

\section{Tools and outcome measures:}

The primary outcomes were the knowledge scores regarding HIV infection and antiretroviral drugs as well as the percentage of medical adherence. Demographic data and knowledge questionnaire applied in this study were adapted from our previous work ${ }^{[14]}$. Thirty questions with 34 points were found in knowledge questionnaire. The contents in questionnaire were separated into 2 parts as follows: disease knowledge (true/false questions; 20 total points) and medication knowledge (10 questions; 14 points). The medication knowledge questionnaire, however, was composed of four sections. The first section focused on general information of antiretroviral drugs (true/false question; 7 points). The second section was identification of recently used medication (1 point). The third section was knowledge on the adverse drug reaction of recently used medication ( 3 points). The last one was knowledge on medical precaution/contraindication (3 points).

Medical adherence was measured using self-reported adherence and pill count method. The self-reported

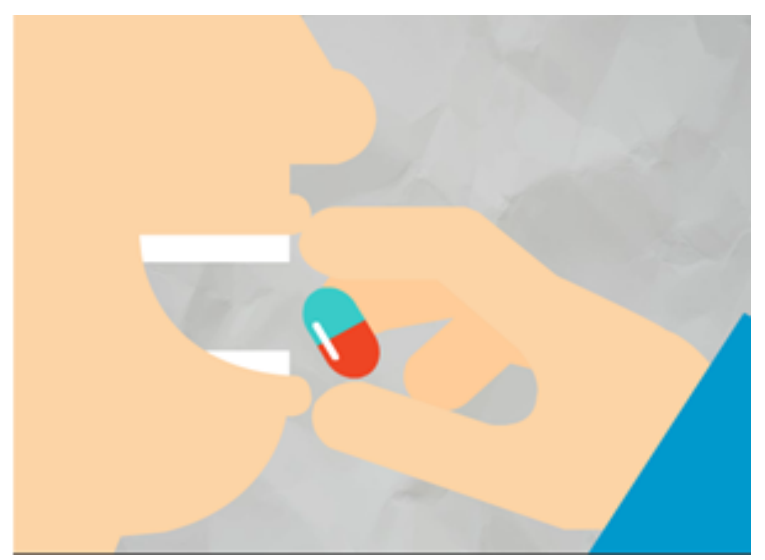

May-June 2021 


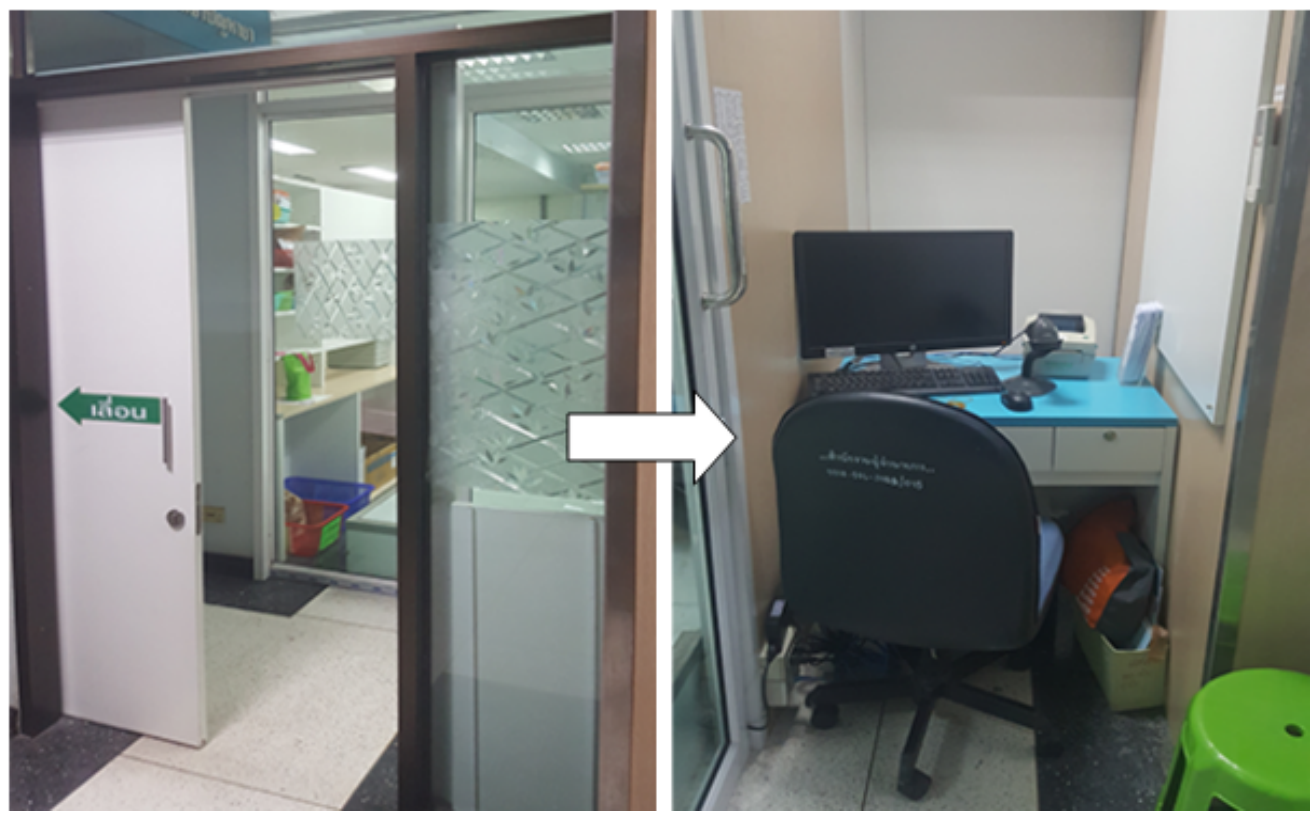

Fig. 2: Room for providing MIM to patients in study group

adherence questionnaire was adapted from the surveys of Adult Acquired immunodeficiency syndrome (AIDS) clinical trials group (AACTG) ${ }^{[17]}$. Good adherence $(100 \%)$ indicated that subjects had never forgotten to take medicine. The pill count method was performed by pharmacist. Both methods would be calculated to render the percentage of medical adherence from the following formula.

Total dose of drug taken/Total dose of drug prescribed $\times 100$

If there was more than one medicine on the prescription, the average of all percentages would be calculated and represent the adherence.

\section{Outcome assessment:}

As soon as subjects arrived the clinic on the first visit, they were asked to fill demographic questionnaire, knowledge questionnaire and self-reported adherence questionnaire. The remaining antiretroviral pills were counted and recorded. Knowledge scores obtained during this period were used as pretest data. MIM was provided afterward only to subjects in the study group for 15-20 min. Subjects in both groups subsequently received routine counseling regarding HIV disease and medications by clinical pharmacist. After the counseling process, all subjects were asked to re-answer the same knowledge questionnaire. Knowledge scores obtained after counseling process were used as posttest data. On the second visit (1 mo later), knowledge scores were retested and recorded as follow-up test data and the medical adherence was measured using the same tools which were done on the first visit.

\section{Data analysis:}

SPSS statistical program was used for data analysis with the significance level at a p-value less than 0.05. Demographic characteristics of patients were summarized as frequency, percentage, mean and standard deviation. Categorical factors were examined by Chi-squares test or Fisher's exact test (if the expected value was less than 5). Differences in means between two groups were analyzed by independent sample t-test or Mann-Whitney U test (if data distribution were not normal). Two way mixed model analysis of variance (ANOVA) with between subjects variable (Group: study and control) and within subjects variable (Time: pretest, posttest and follow-up test) was utilized to compare mean differences of knowledge scores. Bonferroni post hoc t-tests method was further applied if the differences were significance. For medical adherence results, Wilcoxon signed-rank test was used to compare mean percentage differences for paired data from the first and second visits in each group as well as Mann-Whitney $U$ test employed for independent subjects.

\section{RESULTS AND DISCUSSION}

Table 1 presented the demographic characteristics of participants. There was no statistical difference in any characteristics between groups. The average age for all subjects was $41 \mathrm{y}$ old. Most of them were males with at least primary school education. They had a good level of cluster of differentiation 4 (CD4) and viral load. Mean treatment duration for both groups was longer than $5 \mathrm{y}$. Despite taking concomitant drugs, most of them were 
vitamin supplements. About $60 \%$ of participants took none fixed drug combination regimen twice a day.

Knowledge scores regarding HIV infection and antiretroviral drugs were given. The mixed model ANOVA (Table 2) revealed significant effects of group $(\mathrm{p}<0.001)$, time $(\mathrm{p}<0.001)$ and group-bytime interaction $(\mathrm{p}<0.001)$ in knowledge test scores. Bonferroni post-hoc t-tests analysis demonstrated a significant increase in posttest scores and follow-up test scores between two groups $(\mathrm{p}<0.001$, fig. 3). Fig. 4 illustrated significant improvement between pretest and posttest within each group $(\mathrm{p}<0.001)$.
It should be noticed that knowledge test scores on both groups were significantly improved after subjects received the counseling and the study group had significantly higher knowledge scores on the followup test than those in the control group. However, knowledge scores of participants in study group on the follow-up test were a little higher as compare to those in the posttest despite being tested 1 mo apart.

Table 3, the mean percentages of medical adherence in study group, measured by pill count and self-reported adherence method increased after counseling. The mean percentage of medical adherence measured by the

\section{TABLE 1: DEMOGRAPHIC CHARACTERISTICS OF PARTICIPANTS IN TWO GROUPS}

\begin{tabular}{|c|c|c|c|}
\hline Study variable & Study $(n=34)$ & Control $(n=35)$ & $\mathrm{p}$-value \\
\hline Age, years (mean, SD) & $42.85(10.6)$ & $40.34(11.2)$ & $0.341^{*}$ \\
\hline \multicolumn{4}{|l|}{ Gender (n, \%) } \\
\hline Male & $21(55.3 \%)$ & 17 (44.7 \%) & \multirow[t]{2}{*}{$0.271^{* *}$} \\
\hline Female & $13(41.9 \%)$ & $18(58.1 \%)$ & \\
\hline \multicolumn{4}{|l|}{ Education level (n, \%) } \\
\hline Primary school & $14(50.0 \%)$ & $14(50.0 \%)$ & \multirow{3}{*}{$0.871^{* *}$} \\
\hline Secondary school & $13(52.0 \%)$ & $12(48.0 \%)$ & \\
\hline$\geq$ Diploma & $7(43.8 \%)$ & $9(56.2 \%)$ & \\
\hline CD4 cell count, cell/mm³ (mean, SD) & $457.15(247.6)$ & $471.31(264.3)$ & $0.819^{*}$ \\
\hline \multicolumn{4}{|l|}{ Viral load, copies/ml (n, \%) } \\
\hline$<40$ & $25(48.1 \%)$ & 27 (51.9 \%) & \multirow[t]{2}{*}{$0.673^{*+*+}$} \\
\hline$>40$ & $3(60 \%)$ & $2(40 \%)$ & \\
\hline \multicolumn{4}{|l|}{ Concomitant drug $(n, \%)$} \\
\hline Yes & $28(53.8 \%)$ & $24(46.2 \%)$ & \multirow[t]{2}{*}{$0.184^{* *}$} \\
\hline No & $6(35.3 \%)$ & $11(64.7 \%)$ & \\
\hline \multicolumn{4}{|l|}{ Combination antiretroviral drug (n, \%) } \\
\hline Yes & $15(53.6 \%)$ & $13(46.4 \%)$ & \multirow[t]{2}{*}{$0.555^{* *}$} \\
\hline No & $19(46.3 \%)$ & $22(53.7 \%)$ & \\
\hline \multicolumn{4}{|l|}{ Medication regimen $(\mathrm{n}, \%)$} \\
\hline One daily dose & $9(42.9 \%)$ & $12(57.1 \%)$ & \multirow[t]{2}{*}{$0.481^{* *}$} \\
\hline Two daily dose & $25(52.1 \%)$ & $23(47.9 \%)$ & \\
\hline
\end{tabular}

SD stands for standard deviation, "Based on independent sample t-test, "'Based on Chi-squared test, "'**Based on Fisher's exact test

TABLE 2: TWO WAY MIXED MODEL ANOVA RESULTS OF KNOWLEDGE TEST SCORES

\begin{tabular}{|c|c|c|c|c|c|c|}
\hline \multirow{2}{*}{ Groups } & \multicolumn{3}{|c|}{ Knowledge test scores mean (SD) } & \multicolumn{3}{|c|}{ Significance F (p-value) } \\
\hline & Pretest & Posttest & Follow-up test & Group & Time & Groupxtime \\
\hline $\begin{array}{l}\text { Study } \\
(n=34)\end{array}$ & $22.09(4.59)$ & $29.03(3.96)$ & $29.18(3.84)$ & \multirow{2}{*}{$33.606(<0.001)$} & \multirow{2}{*}{$79.984(<0.001)^{*}$} & \multirow{2}{*}{$25.034(<0.001)^{*}$} \\
\hline $\begin{array}{l}\text { Control } \\
(n=35)\end{array}$ & $19.83(5.23)$ & $23.29(4.14)$ & $20.83(4.59)$ & & & \\
\hline
\end{tabular}

SD stands for standard deviation, "Based on Mauchly's test for sphericity assumed $(p=0.146)$

TABLE 3: COMPARISON OF MEDICAL ADHERENCE BETWEEN FIRST AND SECOND VISITS IN EACH GROUP

\begin{tabular}{lccc}
\hline \multirow{2}{*}{ Group of participants } & \multicolumn{3}{c}{ Percentage of medical adherence } \\
\cline { 2 - 3 } Pill count method & First visit Mean (SD) & Second visit Mean (SD) & p-value $^{*}$ \\
Study $(n=34)$ & $98.85(2.30)$ & $99.68(1.07)$ & 0.014 \\
Control $(n=35)$ & $98.54(2.23)$ & $98.40(3.17)$ & 0.715 \\
Self-reported adherence method & & & \\
Study $(n=34)$ & $98.09(3.86)$ & $98.76(3.21)$ & 0.391 \\
Control $(n=35)$ & $96.91(3.44)$ & $96.80(3.92)$ & 0.793 \\
\hline
\end{tabular}

SD stands for standard deviation, "Based on Wilcoxon signed-rank test 
pill count method also revealed a significant increase, $(p=0.014)$. On the other hand, there was no statistical

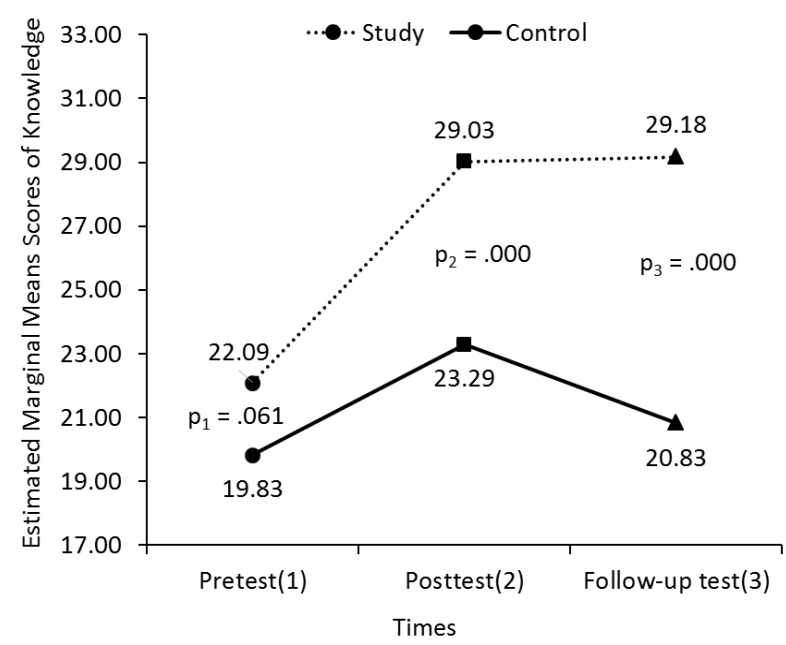

Fig. 3: Pairwise comparisons of knowledge test scores over times $p_{1}$ stands for $p$-value between two groups in pretest, $p_{2}$ stands for $p$-value between two groups in posttest, $p_{3}$ stands for $p$-value between two groups in follow-up test

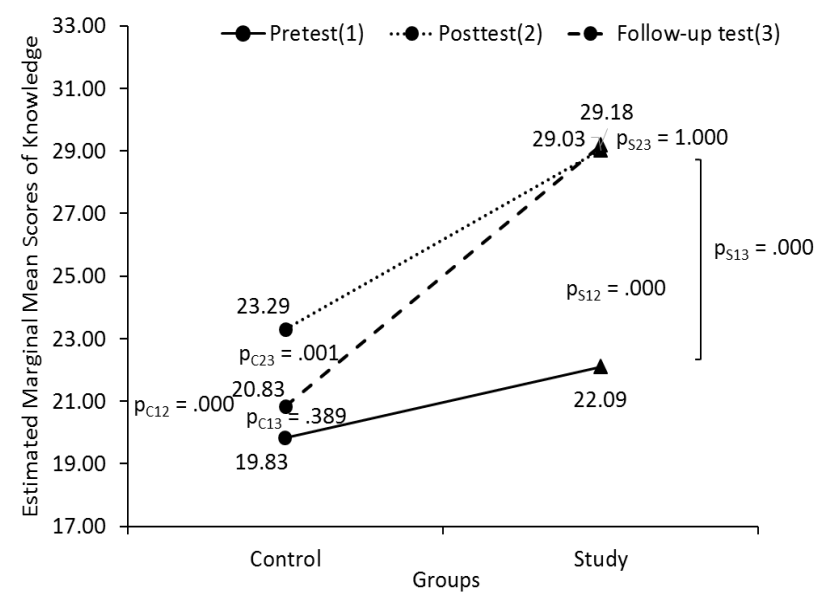

Fig. 4: Pairwise comparisons of knowledge test scores over groups

$\mathbf{p}_{\mathrm{C} 12}$ stands for $p$-value between pretest and posttest means in control group, $p_{\mathrm{C} 13}$ stands for $p$-value between pretest and follow-up test means in control group, $p_{\mathrm{C}_{23}}$ stands for $p$-value between posttest and follow-up test means in control group, $p_{\mathrm{s12}}$ stands for $p$-value between pretest and posttest means in study group, $p_{\mathrm{s} 13}$ stands for $p$-value between pretest and follow-up test means in study group, $p_{\mathrm{s} 23}$ stands for $p$-value between posttest and follow-up test means in study group difference $(\mathrm{p}=0.391)$ in mean percentage of medical adherence measured by self-reported adherence method. Additionally, the mean percentages of medical adherence measured by both methods on the second visit in study group were significantly greater than those in the control group $(\mathrm{p}=0.030$ and $\mathrm{p}=0.021)$ (Table 4$)$.

A number of studies have been attempting to integrate technologies into the counseling given by healthcare providers in HIV clinics. The technologies were tested and showed the effectiveness ${ }^{[16,18-24]}$. However, such technologies are sometimes impractical to be used because of difference of the HIV clinic. This study adopted the concept of the motion infographics to improve the media that is easy to use, able to publicize in various channels and practical for using in HIV clinics in Thailand.

The results of knowledge test scores were consistent with an increase in the percentage of medical adherence. This was consistent with previous studies suggesting that infographic media is more attractive to the audiences than other conventional communication means $^{[11-13]}$.

Subjects in study group had significantly higher knowledge test scores regarding HIV infection and antiretroviral drugs, coinciding with previous reports suggesting that integrating technology into the counseling better improved the knowledge in patients not doing so ${ }^{[16,21]}$. Interestingly, this knowledge scores were not decreased after the period of $1 \mathrm{mo}$, in accordance with the study of Turk et al. ${ }^{[1]}$, suggesting that "infographic affects the long-term memory".

The results indicated that medical adherence was improved when MIM was provided to patients. This is in accordance with previous studies with the results demonstrating good medical adherence ${ }^{[16,18-24]}$. It was also implied that utilization of technology acted as a tool to convey medical information during counseling to improve medical adherence of patients compared with no technology.

It should be noted that the percentage of medical adherence using the pill count method was slightly

TABLE 4: COMPARISON OF MEDICAL ADHERENCE BETWEEN STUDY AND CONTROL GROUPS IN SECOND VISIT

\begin{tabular}{lccc}
\hline \multirow{2}{*}{ Methods } & \multicolumn{3}{c}{ Percentage of medical adherence } \\
\cline { 2 - 4 } & Study mean (SD) & Control mean (SD) & $\mathrm{p}^{-v a l u e}$ \\
\hline Pill count method & $99.68(1.07)$ & $98.40(3.17)$ & 0.030 \\
Self-reported adherence method & $98.76(3.21)$ & $96.80(3.92)$ & 0.021 \\
\hline
\end{tabular}

SD stands for standard deviation, "Based on Mann-Whitney U test 
higher than the one using self-reported adherence method. As the pill was directly counted by pharmacists, the result then could be classified as good evidence. On the contrary, the result from self-report method was very subjective because the result was reported, based on memory of subjects regarding the delay or missing of medication. Thus, the use of self-report adherence method did not provide any empirical evidence.

The result also presented that very high adherence was found in both study and control groups. This may be due to two possible reasons. Firstly, all HIV patients in Thailand can freely access to antiretroviral drug due to the support by the government through Universal Health Coverage Service Scheme. Secondly, the subjects are well aware of being assessed by counting pills as normal, which is the practice of the hospital pharmacy service during their receiving medical care.

HIV-infected patients receiving antiretroviral drugs had better knowledge on the infection and medications as well as good medical adherence after receiving MIM during counseling. This study provided a strong evidence to support the use of MIM as a counseling tool, which can be used by pharmacists, for patient education.

This was a preliminary study conducting in HIV patients at Saraburi hospital. In addition, clinical evaluation focused only on the medical adherence. No other clinical outcomes, such as CD4 or viral load, were measured to confirm the consistency of medical adherence. As the self-reported adherence method was completed by patients, some of them might not accurately remember if they had missed taking the medication because of the long intervals between visits. Furthermore, this research intended to gain the overview data. So, it did not specify the samples with poor medical adherence. As most of the participants had good medical adherence record, the behavioral change was not clear but visible. Lastly, the knowledge on HIV infection and antiretroviral drugs is only the influencing factor that can be directly provided by pharmacist to improve medical adherence. With technological innovations, various counseling issues can be solved. Treatment effectiveness then may be improved.

Future research should include more subjects with multiple setting. A large number of subjects with poor knowledge regarding the infection and inconsistent medical adherence should be included in order to get more reliable and effective results.

\section{Acknowledgements:}

This research is successfully completed by the generous cooperation of all healthcare providers and patients from the HIV Clinic, Saraburi hospital, Thailand. The authors would like to thank Dr. Krittika Tanyasaensook, Mahidol University for providing information which helps to improve the quality of this work.

\section{Conflicts of interest:}

The authors declared no conflict of interest.

\section{REFERENCES}

1. Kim J, Lee E, Park BJ, Bang JH, Lee JY. Adherence to antiretroviral therapy and factors affecting low medication adherence among incident HIV-infected individuals during 2009-2016: a nationwide study. Sci Rep 2018;8(1):1-8.

2. Paterson DL, Swindells S, Mohr J, Brester M, Vergis EN, Squier C, et al. Adherence to protease inhibitor therapy and outcomes in patients with HIV infection. Ann Intern Med 2000;133(1):21-30.

3. Agu K, Ochei U, Oparah A, Onoh O. Treatment outcomes in patients receiving combination antiretroviral therapy in Central Hospital, Benin City, Nigeria. Trop J Pharm Res 2010;9(1):110.

4. World Health Organization. Consolidated guidelines on the use of antiretroviral drugs for treating and preventing HIV infection: recommendations for a public health approachSecond edition; 2016.

5. Department of Disease Control, Thailand national guidelines on HIV/AIDS treatment and prevention; 2017.

6. Jiamsakul A, Kumarasamy N, Ditangco R, Li PC, Phanuphak $\mathrm{P}$, Sirisanthana $\mathrm{T}$, et al. Factors associated with suboptimal adherence to antiretroviral therapy in Asia. J Int AIDS Soc 2014;17(1):18911.

7. Thammakul D, Krutthakart S, Thepworachai U. Factors affecting the adherence to antiretroviral medication among HIV/AIDS patients. J Res Health Sci 2010;4(2):1-11.

8. Kumkrong C. Relationships of health literacy and knowledge about antiretroviral therapy to medication adherence among people living with HIV. Kuakarun J Nurs 2014;21(2):211-28.

9. Beegel J. Infographic for dummies. John Wiley \& Sons: New Jersey; 2014. p. 306.

10. Sakurada J. Basic infographic. BNN Inc: Bangkok; 2015. p. 192.

11. Turck CJ, Silva MA, Tremblay SR, Sachse SL. A preliminary study of health care professionals' preferences for infographics versus conventional abstracts for communicating the results of clinical research. J Contin Educ Health Prof 2014;34:S36-8.

12. Crick K, Hartling L. Preferences of knowledge users for two formats of summarizing results from systematic reviews: infographics and critical appraisals. PLoS One 2015;10(10):e0140029.

13. Occa A, Suggs LS. Communicating breast cancer screening with young women: An experimental test of didactic and narrative messages using video and infographics. J Health Commun 2016;21(1):1-11.

14. Chongpornchai J, Tanyasaensook K, Sratthaphut L. Development of infographic media to counsel HIV-infected patients receiving antiretrovirals. Thai J Pharm 2017;9(1):145- 
56.

15. Bureau of AIDS, TB and STIs. HIV/AIDs treatment literacy; 2011.

16. Robbins RN, Mellins CA, Leu CS, Rowe J, Warne P, Abrams EJ, et al. Enhancing lay counselor capacity to improve patient outcomes with multimedia technology. AIDS Behav 2015;19(2):163-76.

17. Chesney MA, Ickovics JR, Chambers DB, Gifford AL, Neidig $\mathrm{J}$, Zwickl B, et al. Self-reported adherence to antiretroviral medications among participants in HIV clinical trials: the AACTG adherence instruments. AIDS Care 2000;12(3):25566.

18. Horvath KJ, Oakes JM, Rosser BS, Danilenko G, Vezina H, Amico KR, et al. Feasibility, acceptability and preliminary efficacy of an online peer-to-peer social support ART adherence intervention. AIDS Behav 2013;17(6):2031-44.

19. Fisher JD, Amico KR, Fisher WA, Cornman DH, Shuper PA, Trayling C, et al. Computer-based intervention in HIV clinical care setting improves antiretroviral adherence: the LifeWindows Project. AIDS Behav 2011;15(8):1635-46.
20. Claborn KR, Leffingwell TR, Miller MB, Meier E, Stephens JR. Pilot study examining the efficacy of an electronic intervention to promote HIV medication adherence. AIDS care 2014;26(3):404-9.

21. Brock TP, Smith SR. Using digital videos displayed on personal digital assistants (PDAs) to enhance patient education in clinical settings. Int J Med Inform 2007;76(11-12):829-35.

22. Naar-King S, Outlaw AY, Sarr M, Parsons JT, Belzer M, MacDonell $\mathrm{K}$, et al. Motivational Enhancement System for Adherence (MESA): pilot randomized trial of a brief computer-delivered prevention intervention for youth initiating antiretroviral treatment. J Pediatr Psychol 2013;38(6):638-48.

23. Claborn KR, Fernandez A, Wray T, Ramsey S. Computerbased HIV adherence promotion interventions: a systematic review: Translation Behavioral Medicine. Transl Behav Med 2015;5(3):294-306.

24. Hersch RK, Cook RF, Billings DW, Kaplan S, Murray D, Safren $\mathrm{S}$, et al. Test of a web-based program to improve adherence to HIV medications. AIDS Behav 2013;17(9):2963-76. 